\title{
Minimization of apoptosis-like changes in cryopreserved buffalo bull sperm by supplementing extender with $\mathrm{Bcl}-2$ protein
}

\author{
Jasmer Dalal ${ }^{1}$, Ajeet Kumar ${ }^{1}$, Mrigank Honparkhe ${ }^{1}$, Dipak Deka² and Narinder Singh ${ }^{1}$
}

1. Department of Veterinary Gynaecology and Obstetrics, Guru Angad Dev Veterinary and Animal Sciences University, Ludhiana, Punjab, India; 2. School of Animal Biotechnology, Guru Angad Dev Veterinary and Animal Sciences University, Ludhiana, Punjab, India.

Corresponding author: Ajeet Kumar, e-mail: ajeetvet@yahoo.com,

JD: jasmer.sl.dalal@gmail.com, MH: honparkhem@rediffmail.com, DD: dekadipak@rediffmail.com, NS: narinder2002us@yahoo.com

Received: 28-01-2016, Accepted: 16-04-2016, Published online: 02-05-2016

doi: 10.14202/vetworld.2016.432-436 How to cite this article: Dalal J, Kumar A, Honparkhe M, Deka D, Singh N (2016) Minimization of apoptosis-like changes in cryopreserved buffalo bull sperm by supplementing extender with $\mathrm{BCl}-2$ protein, Veterinary World, 9(5): 432-436.

\begin{abstract}
Aim: This study was aimed at evaluating the anti-apoptotic effects of Bcl-2 protein in cryopreserved buffalo bull sperm.

Materials and Methods: A total 10 ejaculates from two buffalo bulls ( 5 each) were collected using artificial vagina method, and semen was evaluated using a standard protocol. Semen was extended by Tris egg yolk extender supplemented with Bcl-2 protein at 5, 10, and $15 \mu \mathrm{M}$. Semen was cryopreserved at ultra-low temperature using traditional vapor freezing method. Prefreeze and post-thaw semen samples were evaluated for percent motility, viability, hypo-osmotic swelling test (HOST) reactive sperms; status of mitochondrial membrane activity and status of sperm phospholipase A1 and phospholipase A2 activity.

Results: There were no significant effects of Bcl-2 protein supplementation on pre-freeze sperm quality. Percent motility and active mitochondria in post-thaw Bcl-2 supplemented and control groups were also similar. However, viable sperms were significantly $(\mathrm{p}<0.05)$ higher $(74.29 \pm 4.23 \%)$ in Bcl-2 supplemented group $(5 \mu \mathrm{M})$ as compared to control $(51.6 \pm 5.77 \%)$. The proportion of HOST reactive sperms was also higher $(63.1 \pm 6.73 \%)$ in Bcl-2 supplemented $(5 \mu \mathrm{M})$ group as compared to control $(50.7 \pm 6.98 \%)$. The sperm with low PLA activity (non-apoptotic) was significantly $(\mathrm{p}<0.05)$ higher in all the supplemented doses of Bcl-2 protein, i.e., at $5 \mu \mathrm{M}(73.42 \pm 5.79 \%), 10 \mu \mathrm{M}(75.51 \pm 6.22 \%)$, and $15 \mu \mathrm{M}(74.78 \pm 5.89 \%)$ as compared to control $(60.23 \pm 4.45 \%)$. We found that Bcl-2 protein supplementation at $5 \mu \mathrm{M}$ dose improved the postthaw semen quality indicated by higher viability, HOST reactive sperms, and sperm with low PLA activity (non-apoptotic sperms).
\end{abstract}

Conclusion: Bcl-2 protein supplementation exerts its protective effect on spermatozoa against apoptosis-like changes developed during cryopreservation.

Keywords: anti-apoptotic effects, Bcl-2 protein, buffalo bull, semen cryopreservation.

\section{Introduction}

High quality cryopreserved semen is the primary requirement of dairy sector to achieve high conception rates [1]. One of the factors which decrease the frozen semen quality is the development of apoptosis-like changes in sperm during cryopreservation. Various factors have been attributed to the development of apoptosis-like changes such as cryopreservation, heat exposure, radiation, hydrogen peroxide, genetic disturbances, and endocrine disruptions [2,3]. It has been reported that cryofreezing stress is a major contributing factor to induce apoptosis in sperms by increasing (4.5-54.4\%) the proportion of sperm with low mitochondrial membrane potential [4]. Apart from that, several genes and molecules are also responsible for

Copyright: Dalal, et al. Open Access. This article is distributed under the terms of the Creative Commons Attribution 4.0 International License (http://creativecommons.org/licenses/by/4.0/), which permits unrestricted use, distribution, and reproduction in any medium, provided you give appropriate credit to the original author(s) and the source, provide a link to the Creative Commons license, and indicate if changes were made. The Creative Commons Public Domain Dedication waiver (http://creativecommons.org/ publicdomain/zero/1.0/) applies to the data made available in this article, unless otherwise stated. the initiation of apoptosis in sperm such as Bax, Bak, and $\mathrm{p} 53$ proteins [5].

It has been established that $\mathrm{Bcl}-2$ family proteins are located in the outer mitochondrial membrane, wherein Bax induces and Bcl-2 inhibits the release of pro-apoptotic proteins, i.e., cytochrome $\mathrm{C}[6,7]$. The release of cytochrome $\mathrm{C}$ from the mitochondria leads to DNA fragmentation [4], which is an early marker of apoptosis [8]. It is well established that sperm DNA damage is negatively associated with fertilization rate, implantation, and successful pregnancy [9] and higher occurrences of miscarriage [10]. Further, apoptotic sperms with fragmented DNA and asymmetrical membrane result in poor fertility [11]. It has been well established that apoptosis is executed via various proteins, which are regulated by Bcl-2 family members [8]. Bcl-2 is the most important anti-apoptotic protein and its function is related to interfere with mitochondrial apoptosis pathways [12]. So, the supplementation of anti-apoptotic $\mathrm{Bcl}-2$ protein can inhibit the apoptotic pathways $[8,13]$.

The significance of this study is that the supplementation of Bcl-2 protein might reduce the apoptosis-like changes inflicted during cryopreservation. So, 
the post-thaw semen quality may be enhanced by minimizing apoptosis of sperms during cryopreservation by supplementation of Bcl-2 protein.

This study was aimed at accessing the ameliorative effects of Bcl-2 protein on apoptosis-like changes in buffalo bull sperm developed during cryofreezing.

\section{Materials and Methods}

\section{Ethical approval}

The approval from the Institutional Animal Ethics Committee to carry out this study was not required as no invasive technique was used. Semen was being collected and frozen as a routine procedure under progeny testing program.

\section{Selection of buffalo bulls}

Two breeding buffalo bull around 4 years of age maintained at the bull farm, Guru Angad Dev Veterinary and Animal Sciences University, Punjab, India (Latitude/Longitude, $30.55^{\circ} \mathrm{N}, 75.54^{\circ} \mathrm{E}$ ) was included for this study. These bulls were under progeny testing program and were being used for semen collection by artificial vagina method. Bulls were maintained under loose housing system (covered area $-12 \times 10 \mathrm{ft}$ and uncovered area $-25 \times 10 \mathrm{ft}$ ) and standard feeding schedule along with adlib green fodder.

\section{Experimental design}

Five ejaculates from each buffalo bulls were used in this study. Each ejaculate was extended with Tris egg yolk extender as follows. The anti-apoptotic protein Bcl-2 (cat\# Pro-630, Prospec protein specialist) was dissolved in dimethylsulfoxide (DMSO) at $100 \mu \mathrm{M}$ concentration (stock solution). From each extended ejaculates, 4 aliquots were taken. Three aliquots were supplemented with Bcl-2 protein stock solution to make final concentration at 5,10, and $15 \mu \mathrm{M}$. The unsupplemented aliquot was served as control. Semen samples were frozen using traditional vapor freezing method. The quality of pre-freeze and post-thaw semen in terms of \% individual motility, \% viability, \% hypo-osmotic swelling test (HOST) reactive sperms, \% active mitochondria, and $\%$ sperm with low phospholipase A (PLA) activity (non-apoptotic sperms) was evaluated. Before recording the observations, 5 dummy trials were conducted to standardize the protocol. The incubation time for fluorescent imaging was also standardized accordingly. Thereafter, actual observations were recorded from a total of 10 ejaculates. Moreover, our aim was not to study the apoptosis-like changes due to bull variations.

The $\%$ individual motility was assessed manually under $20 \times$ objective of phase contrast microscope (Nikon Eclipse E 200). The live sperm count was determined through Eosin-Nigrosin staining technique [14]. The HOST was performed to assess the functional integrity of sperm membrane [15].

Evaluation of mitochondrial membrane activity in Bcl-2 supplemented pre-freeze and post-thaw semen

Mitochondrial membrane potential was assessed using fluorescent dye tetramethylrhodamine, methyl ester (TMRM, Life Technologies; Cat\# T-668). Stock solution $(10 \mathrm{mM})$ was prepared in DMSO and stored at $-20^{\circ} \mathrm{C}$ until use. A working solution of $50 \mu \mathrm{M}$ was prepared and stored at $-20^{\circ} \mathrm{C}$. Semen samples (pre-freeze and post-thaw; $250 \mu \mathrm{l}$ ) were taken into microcentrifuge tubes, and $1 \mathrm{ml}$ of phosphate-buffered saline (PBS) was added to them. The samples were given 2 washings with PBS by centrifuging at $1000 \mathrm{RPM}$ for $5 \mathrm{~min}$ at $37^{\circ} \mathrm{C}$. Then, $5 \mu \mathrm{l}$ of working TMRM solution was added to each sample and incubated at $37^{\circ} \mathrm{C}$ for $90 \mathrm{~min}$. After incubation, washing was done with $1 \mathrm{ml}$ of PBS at $1000 \mathrm{RPM}$ for $5 \mathrm{~min}$ at $37^{\circ} \mathrm{C}$ to remove all the unbound dye. The pellet was mixed well with $500 \mu \mathrm{l}$ of PBS. On a micro slide, $10 \mu \mathrm{l}$ of washed sample and $8 \mu \mathrm{l}$ of ProLong Gold Antifade Mountant with DAPI (Life Technologies, Cat\# P36941) were taken and covered with coverslip. The slide was kept at $4^{\circ} \mathrm{C}$ after wrapping it in aluminum foil for $10 \mathrm{~min}$. The slide was examined under an upright fluorescent microscope (Nikon) with DAPI filter (420-480 nm) as shown in Figure-1, FITC filter $(510-580 \mathrm{~nm})$ as shown in Figure-2, and TRITC filter $(530-580 \mathrm{~nm})$ as shown in Figure-3. Around 100 sperms were observed for high or low

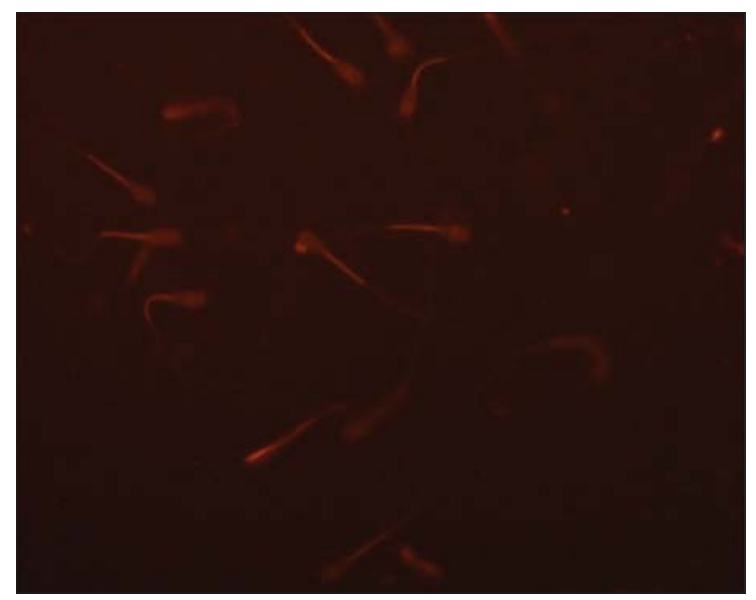

Figure-1: Sperm mitochondria stained with TMRM, TRITC filter $(400 x)$

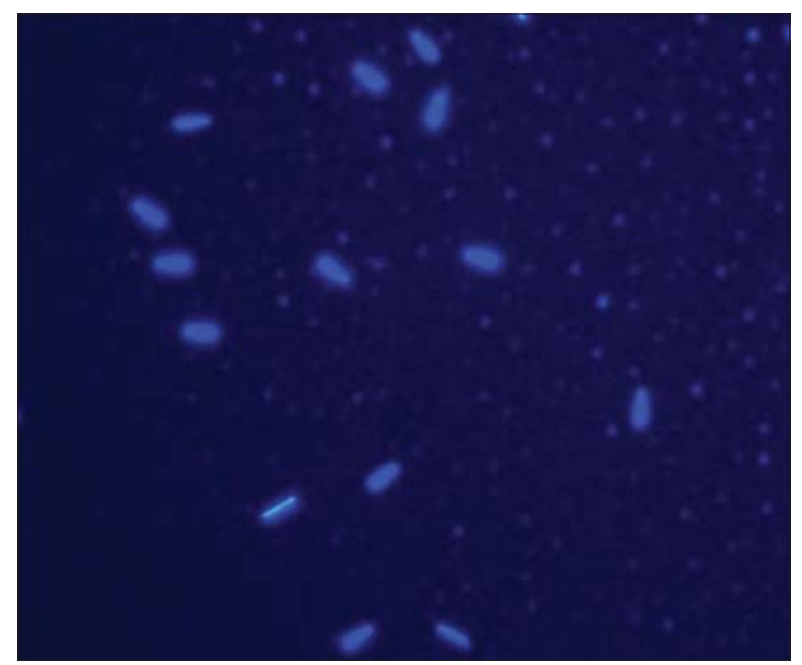

Figure-2: Sperm nucleus stained with DAPI (400x). 
fluorescence in midpiece region as an indicator of mitochondrial membrane activity.

\section{Evaluation of sperm phospholipase activity in Bcl-2 supplemented pre-freeze and post-thaw semen}

Sperm phospholipid membrane was studied using BODIPY C11 fluorescent dye (4,4-difluoro-5,7-dimethyl-4-bora-3a,4a-diaza-s-indacene-3-undecanoic acid (BODIPY C11 FL, Life Technologies, Cat\# D 3862). Stock solution (100 mM) was prepared in DMSO and stored at $-20^{\circ} \mathrm{C}$. A working solution of $20 \mu \mathrm{M}$ was prepared and stored at $-20^{\circ} \mathrm{C}$. Semen samples (pre-freeze and post-thaw; $250 \mu \mathrm{l}$ ) were taken into microcentrifuge tubes, and $1 \mathrm{ml}$ of PBS was added to them. The samples were given 2 washings with PBS by centrifuging at 1000 RPM for $5 \mathrm{~min}$ at $37^{\circ} \mathrm{C}$. Then, $30 \mu \mathrm{l}$ of working BODIPY solution was added to each sample and incubated for $45 \mathrm{~min}$ at $37^{\circ} \mathrm{C}$. After incubation, washing was done with $1 \mathrm{ml}$ of PBS at $1000 \mathrm{RPM}$ for $5 \mathrm{~min}$ at $37^{\circ} \mathrm{C}$ to remove all the unbound dye. The pellet was mixed well with $500 \mu \mathrm{l}$ of PBS. On a micro slide, $10 \mu \mathrm{l}$ of sample and $8 \mu \mathrm{l}$ of ProLong Gold Antifade Mountant with DAPI (Life Technologies, Cat\# P36941) were taken and covered with coverslip. The slides were kept at $4^{\circ} \mathrm{C}$ after wrapping it in aluminum foil for $10 \mathrm{~min}$. Glass slides were examined under an upright fluorescent microscope (Nikon) with DAPI filter (420-480 nm) and FITC filter $(510-580 \mathrm{~nm})$ as shown in Figure-4 and TRITC filter $(530-580 \mathrm{~nm})$. Around 100 sperms in different fields were observed, and normal sperm without fluorescence was calculated and taken as \% sperm with low PLA1 and PLA2 activity.

\section{Statistical analysis}

The arcsine transformation of percent data was carried out. The data were analyzed with one-way analysis of variance and Games-Howell post-hoc test using IBM SPSS Version 20. The data are presented as means and standard errors for all variables. $p<0.05$ was considered as significant.

\section{Results}

In our study, Tris extender was supplemented with Bcl-2 protein in the final concentration at 5, 10, and $15 \mu \mathrm{M}$ and evaluated the pre-freeze and post-thaw semen samples in terms of percent individual motility, viability, HOST reactive sperms, mitochondrial membrane activity, and sperm PLA activity status. Data obtained was analyzed and presented in Table-1.

\section{Effects of various doses of $\mathrm{Bcl}-2$ protein supplemen-} tation at pre-freeze stage

In pre-freeze semen, \% individual motility, viability, HOST reactive sperm, active mitochondria and sperms with low PLA activity were similar $(\mathrm{p}>0.05)$ between control and various supplementation groups.

\section{Effects of various doses of $\mathrm{Bcl}-2$ protein supplemen-} tation at post-thaw stage

The $\%$ individual motility and \% active mitochondria were also similar in post-thaw semen

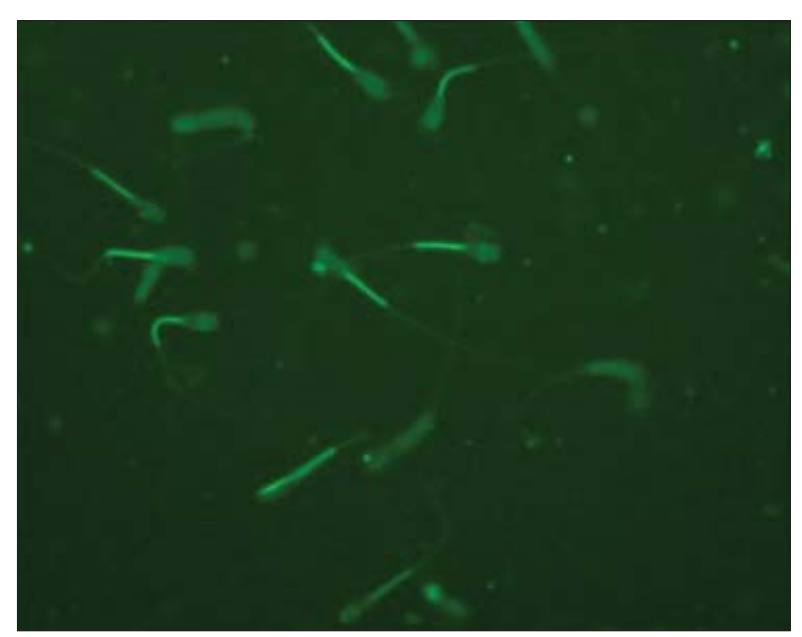

Figure-3: Sperm mitochondria stained with TMRM, FITC filter (400x).

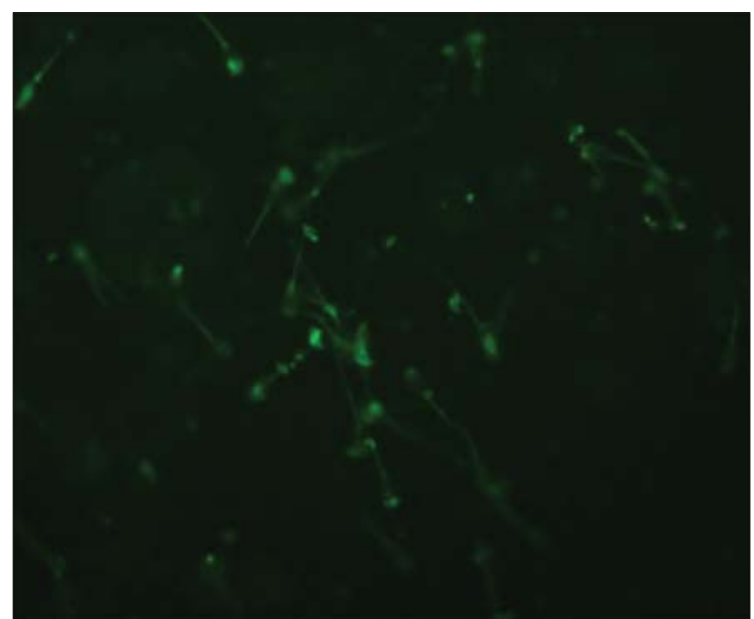

Figure-4: Sperm plasma membrane stained with Bodipy C11, FITC filter (400x).

samples. The $\%$ viable $(74.29 \pm 4.23$ vs. $51.6 \pm 5.77)$ and $\%$ HOST reactive sperms $(63.1 \pm 6.73$ vs. $50.7 \pm 6.98)$ were significantly $(\mathrm{p}<0.05)$ higher in Bcl-2 supplemented samples $(5 \mu \mathrm{M})$ as compared to control. The $\%$ sperms with low PLA activity (non-apoptotic) were significantly $(\mathrm{p}<0.05)$ higher in all supplementation doses of Bcl-2 protein, i.e., at $5 \mu \mathrm{M}(73.42 \pm 5.79)$, $10 \mu \mathrm{M}(75.51 \pm 6.22)$, and $15 \mu \mathrm{M}(74.78 \pm 5.89)$ as compared to control $(60.23 \pm 4.45)$.

\section{Discussion}

This is the first report to minimize the apoptosis-like changes developed during semen cryopreservation by supplementing extender with $\mathrm{Bcl}-2$ protein. In our study, Bcl-2 protein supplementation did not show any effect on individual motility and mitochondrial activity. However, Bcl-2 supplementation at $5 \mu \mathrm{M}$ improved viability, membrane integrity, and minimized the PLA activity. A similar study has not been conducted to compare the results of this study. Cryopreservation affects sperm motility, vitality, DNA integrity, and increases in intracellular $\mathrm{Ca}^{2+}$ concentration which leads to the release of pro-apoptotic factors 
Table-1: Effects of supplementation of $\mathrm{Bcl}-2$ protein at various concentrations on semen quality at pre-freeze and post-thaw stage.

\begin{tabular}{|c|c|c|c|c|c|c|c|c|}
\hline \multirow{2}{*}{$\begin{array}{l}\text { Parameters } \\
(\%)\end{array}$} & \multicolumn{4}{|c|}{ Pre-freeze } & \multicolumn{4}{|c|}{ Post-thaw } \\
\hline & Control & $5 \mu \mathrm{M}$ & $10 \mu M$ & $15 \mu M$ & Control & $5 \mu \mathrm{M}$ & $10 \mu \mathrm{M}$ & $15 \mu M$ \\
\hline Motility & $85 \pm 8.11$ & $89.0 \pm 8.31$ & $84.0 \pm 7.46$ & $85.0 \pm 8.36$ & $45.8 \pm 7.35$ & $40.29 \pm 7.53$ & $33.41 \pm 5.62$ & $40.23 \pm 6.22$ \\
\hline Live & $89.19 \pm 5.56$ & $92.2 \pm 5.89$ & $80.5 \pm 4.22$ & $82.12 \pm 7.60$ & $51.6 \pm 5.77^{a}$ & $74.29 \pm 4.23^{\mathrm{b}}$ & $49.57 \pm 8.72$ & $53.32 \pm 7.57$ \\
\hline HOST & $84.76 \pm 8.83$ & $71.2 \pm 4.65$ & $73.5 \pm 6.56$ & $67.2 \pm 4.76$ & $50.7 \pm 6.98^{a}$ & $63.1 \pm 6.73^{\mathrm{b}}$ & $42.43 \pm 5.66$ & $37.76 \pm 5.88$ \\
\hline $\begin{array}{l}\text { Active } \\
\text { mitochondria }\end{array}$ & $80.11 \pm 5.77$ & $83.6 \pm 4.67$ & $85.13 \pm 6.34$ & $91.22 \pm 3.94$ & $67.1 \pm 2.44$ & $79.3 \pm 4.67$ & $72.4 \pm 2.33$ & $78.5 \pm 3.68$ \\
\hline $\begin{array}{l}\text { Low PLA } \\
\text { activity }\end{array}$ & $85.23 \pm 5.43$ & $75.45 \pm 6.37$ & $81.35 \pm 4.92$ & $85.61 \pm 5.92$ & $60.23 \pm 4.45^{a}$ & $73.42 \pm 5.79^{b}$ & $75.51 \pm 6.22^{b}$ & $74.78 \pm 5.89^{b}$ \\
\hline
\end{tabular}

Values marked with different superscripts differ significantly $(p<0.05)$ in the row. HOST: Hypo-osmotic swelling test, PLA: Phospholipase A

in the cytoplasm. The anti-apoptotic effects of Bcl-2 are well established in human sperm [16]. Bcl-2 inhibits caspase activity either by preventing the release of cytochrome $\mathrm{C}$ from the mitochondria and/or by binding to the apoptosis-activating factor-1 [17]. The primary role of the anti-apoptotic protein BCL-2 is to prevent the action of pro-apoptotic proteins responsible for pore formation in the mitochondria [18]. Bcl-2 and Bax ratio in sperm determines the fate of sperm where Bcl-2 inhibits and Bax promotes the apoptosis [6,7]. The apoptosis-promoting factor Bax has been detected in bovine spermatozoa, whereas anti-apoptotic factor Bcl-2 has not been detected [19]. The dynamic balance that occurs between anti-apoptotic members such as Bcl-2 and pro-apoptotic members helps determine whether the cell initiates apoptosis $[20,21]$. So, exogenous supplementation of Bcl-2 might have provided protective effects to sperm against apoptosis during cryopreservation. Bcl-2 protein inhibits mitochondrial and membranous pathway of apoptosis by preventing $\mathrm{Ca}^{+}$influx and phospholipase dependent externalization of phosphatidylserine [22]. In normal sperm, phosphatidylserine is sequestered in the inner layer of the membrane by various translocases, which maintain asymmetry of sperm plasma membrane. Further, it has also been observed that in boar sperm with higher extra or intracellular phospholipase activity by the combined action of lipid peroxidation and $\mathrm{Ca}^{2+}$ on membrane phospholipids ultimately alters its structure and initiates membrane degradation [23]. Membrane lysis and cell death could result from excessive phospholipase enzyme activity [24] which ultimately reduces the semen quality.

In this study, two fluorescent staining Probes such as TMRM and BODIPY C11 FL were used. TMRM is a cell-permeant, red-orange fluorescent dye, bearing a delocalized positive charge, which readily enters the negatively charged mitochondria, where it accumulates in an inner membrane potential-dependent manner [25]. TMRM distributes itself within polarized mitochondria in a Nernstian manner. Membrane potential driven accumulation of TMRM within the inner membrane of healthy functioning mitochondria results in an increase in TMRM associated orange fluorescence. In case where the mitochondrial membrane potential collapses in apoptotic or metabolically stressed cells, TMRM dye disperses throughout the cell cytoplasm at a concentration that yields minimal fluorescence on excitation in the optimal wavelength region.

Molecular Probe BODIPY C11 FL substrate has been specifically designed to provide a continuous fluorescence response to PLA. The BODIPY C11 FL probe is incorporated in sperm membranes. The proximity of BODIPY C11 FL fluorophores on adjacent phospholipid acyl chains results in self-quenching of fluorescence, which is alleviated by PLA1 or PLA2 mediated release of a BODIPY C-11 FL-labeled fatty acid (BODIPY FL C11). Spermatozoa with deteriorated membrane and externalized phosphatidylserine are characterized by an increased lyso-phosphatidylcholine content that is likely generated by phospholipases [26]. Externalization of phosphatidylserine from the inner leaflet to the outer leaflet of membrane is considered as a sign of early apoptosis [27]. Using this probe, we assessed the apoptotic sperm with fluorescence. Sperm without fluorescence indicated low activity of phospholipase.

\section{Conclusion}

On the basis of this study, it could be concluded that $\mathrm{Bcl}-2$ protein supplementation exerts its protective effect on spermatozoa against apoptosis-like changes developed during cryopreservation. Bcl-2 protein supplementation in the extender at $5 \mu \mathrm{M}$ improved post-thaw semen quality in terms of percent viability, HOST reactive sperms, and sperms with low PLA activity (non-apoptotic sperms).

\section{Authors' Contributions}

The entire work was carried out by JD, for his Masters degree. Planning and execution of work were under the supervision of AK. Data analysis was carried out by $\mathrm{MH}$. The mitochondrial membrane activity was assessed under the supervision of DD and NS. The manuscript was written by JD and edited by AK. All authors read and approved the final manuscript.

\section{Acknowledgments}

This work was supported by the Department of Biotechnology (DBT), Government of India, vide 
BT/PR3596/AAQ/01/483/2011 under the project "Improvement in fertilizability of cryopreserved buffalo bull semen by minimizing cryocapacitation and apoptosis-like changes."

\section{Competing Interests} interests.

The authors declare that they have no competing

\section{References}

1. Chaveiro, A., Machado, L., Frijters, A., Engel, B. and Woelders, H. (2006) Improvement of parameters of freezing medium and freezing protocol for bull sperm using two osmotic supports. Theriogenology, 65(9): 1875-1890.

2. Aitken, R.J. and Baker, M.A. (2013) Causes and consequences of apoptosis in spermatozoa; Contributions to infertility and impacts on development. Int. J. Dev. Biol., 57(2-4): 265-272.

3. Aitken, R.J. and Koppers, A.J. (2011) Apoptosis and DNA damage in human spermatozoa. Asian J. Androl., 13: 36-42.

4. Martin, G., Cagnon, N. and Sabido, O. (2007) Kinetics of occurrence of some features of apoptosis during the cryopreservation process of bovine spermatozoa. Hum. Reprod., 22: $380-388$.

5. Dogan, S., Mason, M.C., Govindaraju, A., Belser, L., Kaya, A., Stokes, J., Rowe, D. and Memili, E. (2013) Interrelationships between apoptosis and fertility in bull sperm. J. Reprod. Dev., 59: 18-26.

6. Korsmeyer, S.J., Knudson, C.M., Tung, K.S., Tourtellotte, W.G. and Brown, G.A. (1995) Bax-deficient micewith lymphoid hyperplasia and male germ cell death. Science, 270: 96-99.

7. Korsmeyer, S.J., MacGregor, G.R., Ross, A.J., Richardson, L.L., Mahar, P.L., Waymire, K.G., Knudson, C.M., Thompson, C.B., Handel, M.A. and Russell, L.D. (1999) Analysis of Bcl2 family function in spermatogenesis. In: Goldberg, E., editor. XV th Testis Workshop. Serono Symposia USA, Inc., Louisville, Kentucky. p55.

8. Nasimi, P. and Roohi, S. (2012) Cell Death in Animals and Plants; Apoptosis, Necrosis \& Autophagy. Islamic Azad University, Masjed Soleyman Press, Masjed Soleyman.

9. Simon, L., Lutton, D., McManus, J. and Lewis, S.E. (2011) Sperm DNA damage measured by the alkaline Comet assay as an independent predictor of male infertility and in vitro fertilization success. Fertil. Steril., 95: 652-657.

10. Aitken, R.J., Findlay, J.K., Hutt, K.J. and Kerr, J.B. (2011) Apoptosis in the germ line. Reproduction, 141: 139-150.

11. Anzar, M., Erickson, L. and Kroetsch, T. (2015) Relationship between sperm apoptosis and bull fertility: In vivo and in vitro studies. Reprod. Fertil. Dev., 2: 58.

12. Belka, C. and Budach, W. (2002) Anti-apoptotic Bcl-2 proteins: Structure, function and relevance for radiation biology. Int. J. Radiat. Biol., 78(8): 643-658.

13. Kontos, C.K., Christodoulou, M.L. and Scorilas, A. (2013) Apoptosis-related BCL2-family members: Key players in chemotherapy. Anticancer Agents Med. Chem., 13: 1-22.

14. Blom, E. (1977) The evaluation of bull semen with special reference to its use in artificial insemination. Anim. Breed. Abst., 19: 648.

15. Jeyendran, R.S., Vander-Ven, H.H., Perez-Pelaez, M., Crabo, B.G. and Zanevld, L.J.D. (1984) Development of an assay to assess the functional integrity of the human sperm membrane and its relationship to other semen characters. J. Reprod. Fertil., 70: 219-228.

16. Oldereid, N.N., Angelis, P.D., Wiger, R. and Clausen, O.P. (2001) Expression of Bcl-2 family proteins and spontaneous apoptosis in normal human testis. Mol. Hum. Reprod., 7(5): 403-408.

17. Deming, P.B., Schafer, Z.T., Tashker, J.S., Potts, M.B., Deshmukh, M. and Kornbluth, S. (2004) Bcr Abl-mediated protection from apoptosis downstream of mitochondrial cytochrome C release. Mol. Cell. Biol., 23: 10289-10299.

18. Llambi, F., Moldoveanu, T., Tait, S.W., Bouchier-Hayes, L., Temirov, J., McCormick, L.L., Dillon, C.P. and Green, D.R. (2011) A unified model of mammalian BCL-2 protein family interactions at the mitochondria. Mol. Cell., 44(4): 517-531.

19. Reed, J.C. (1997) Double identity for proteins of the Bcl-2 family. Nature, 387: 773-776.

20. Strasser, A., Cory, S. and Adams, J.M. (2011) Deciphering the rules of programmed cell death to improve therapy of cancer and other diseases. EMBO J., 30(18): 3667-3683.

21. Garcia-Saez, A.J. (2012) The secrets of the Bcl-2 family. Cell Death Differ., 19(11): 1733-1740.

22. Vines, C.M. and Bill, C.A. (2015) Phospholipases. In: Encyclopedia of Life Sciences. Chichester: John Wiley \& Sons Ltd., p1-9.

23. Robertson, L., Bailey, J.L. and Buhr, M.M. (1990) Effects of cold shock and phospholipase $\mathrm{A}_{2}$ upon intact boar spermatozoa and sperm head plasma membranes. Mol. Reprod. Dev., 26: 143-149.

24. Shier, W.T. (1979) Activation of high levels of endogenous phospholipase $\mathrm{A}_{2}$ in cultured cells. Proc. Natl. Acad. Sci. USA.,76: 195-199.

25. Farkas, D.L., Febbroriello, W.P., Carson, J.H. and Loew, L.M. (1989) Simultaneous imaging of cell and mitochondrial membrane potentials. Biophys. J., 56: 1053-1069.

26. Glander, H.J., Schiller, J., Suss, R., Paasch, U., Grunewald, S. and Arnhold, J. (2002) Deterioration of spermatozoal plasma membrane is associated with an increase of sperm lyso-phosphatidylcholines. Andrologia, 34(6): 360-366.

27. Tavalaee, M., Deemeh, M.R., Arbabian, M., Kiyani, A. and Nasr-Esfahani,M.H. (2014) Relationship between fertilization rate and early apoptosis in sperm population of infertile individuals. Andrologia, 46: 36-41. 